\title{
In vitro Efficacy of Fungicides and Bioagents against Early Blight of Tomato caused by Alternaria solani
}

\author{
G. K. Sudarshan ${ }^{\text {* }}$, M. S. Nagaraj ${ }^{2}$, N. Thammaiah ${ }^{1}$, S. B. Yogananada ${ }^{2}$, \\ A. P. Mallikarjuna Gowda ${ }^{2}$ and M. K. Prasanna Kumar ${ }^{2}$ \\ ${ }^{1}$ University of Horticultural Sciences, Bagalkot-587104, India \\ ${ }^{2}$ University of Agricultural Sciences, Bengaluru, Karnataka-560065, India \\ *Corresponding author
}

\section{A B S T R A C T}

In vitro evaluation of three contact and five systemic and two combination was carried out under laboratory condition in 2018-19 at Department of Plant Pathology, College of Horticulture, Mysuru by using Potato Dextrose Agar medium (PDA) as basal medium and

\section{Keywords}

Early blight, Alternaria solani, Fungicides, Bio agents

\section{Article Info}

Accepted:

12 August 2020 Available Online: 10 September 2020 six biocontrol agents were evaluated through dual culture technique. The result revealed that, there was significant difference among the fungicides in inhibiting the radial growth of the A. solani. Among the different contact fungicides evaluated against test fungi the least mean per cent inhibition of $78.61 \%$ was recorded in Mancozeb75\%WP and it was found significantly superior over other two fungicides. The least per cent inhibition was noticed in case of Mandipropamid 23.4\% SC which has recorded $18.80 \%$ inhibition. Among the five systemic and two combination fungicides evaluated against A. solani, Hexaconazole @ $0.1 \%$ and $0.15 \%$ has recorded maximum inhibition of mycelial growth of test fungi and which has recorded $86.22 \%$ inhibition followed by $85.00 \%$ inhibition was recorded in Trifloxystrobin 25 + Tebuconazole 50\% WG @ 0.15\%. The least percent inhibition of 53.99\% was recorded in Pyraclostrobin 20\%WG @ $0.05 \%$. The results also indicated that the per cent inhibition was increased by increasing the concentration of fungicides tested. Among the different antagonistic organisms evaluated maximum inhibition of mycelial growth of A. solani was recorded in Trichoderma asperellum (69.69 $\%$ ) followed by Trichoderma harzianum (67.51\%). Among the four bacterial bio agents Bacillus vezelensis has recorded $62.76 \%$ inhibition followed by Pseudomonas putida $(43.13 \%)$ and the least per cent inhibition of mycelial growth was noticed in Pseudomonas fluorescens $(42.19 \%)$ at 5 Days after incubation.

\section{Introduction}

Tomato (Solanum lycopersicum) is one of the important and common vegetable grown in world. Tomatoes are the major dietary source of the antioxidant lycopene, which has been linked to many health benefits including reduced risk of heart disease and cancer. They are also great source of Vitamin C, Vitamin $\mathrm{K}$, Potassium and Folate. The crop is grown for table purpose as well as for development of processed products like Ketchup, Juice, soup etc. In India it was estimated that it was grown in an area of $0.8 \mathrm{M}$ ha and 19.00 MT 
and productivity of 23.75 t/ha (Anonymous, 2018). In Karnataka it was grown mainly in southern parts of the state which include Kolar, Chikkaballapura, Bengaluru rural, Chamarajanagara, Mysuru, Hassan and Mandya. It occupies an area of $0.06 \mathrm{MHa}$ with the production of 2.08 MT and productivity of 32.40 t/ha (Anonymous, 2018).

Tomato early blight caused by Alternaria solani (Ellis and martin) Jones and Grout is one of the most common tomato diseases occurring nearly every season in all tomato growing areas. It affects all aerial parts of the plant including leaves, fruits and stem. It was estimated that disease can leads yield loss up to $78 \%$ (Datar and Mayee, 1978, Chandravanshi et al., 1994). Irregular brown spots with concentric rings on the lower leaves are the typical symptoms of early blight on leaves (Vloutoglou and Kalogerakis, 2000). It occasionally attacks the fruit, producing large sunken black spots at the stem end, which drop prematurely leading to a sever yield loss.

So, attempt was made to evaluate some fungicides and bio agents under In vitro condition to further utilize them in field condition for the integrated management of disease.

\section{Materials and Methods}

The present study was carried out under laboratory condition in 2018-19 at Department of Plant Pathology, College of Horticulture, Mysuru. In vitro evaluation of three contact and five systemic and two combination fungicides were evaluated at different concentrations through poison food technique (Nene and Tapliyal, 1993; Roopa et al., 2014) by using Potato Dextrose Agar medium (PDA) as basal medium and six biocontrol agents were evaluated through dual culture technique. $100 \mathrm{ml}$ of potato dextrose agar medium was prepared in $250 \mathrm{ml}$ conical flask and medium was sterilized at $15 \mathrm{lbs}$ for 15 minutes at $121^{\circ} \mathrm{C}$. Required quantity of test fungicides were calculated and added in the sterilized medium separately. Flasks containing poisoned medium were shaken well to have even and uniform distribution of the fungicides. About $20 \mathrm{ml}$ of poisoned PDA was poured in each of the sterilized petriplates and allowed to solidify. The plates were inoculated by pure culture of Alternaria solani by placing $5 \mathrm{~mm}$ disc of 1 week old pure culture. The disc was transferred aseptically to the petriplates containing the medium with test fungicides. The seven plates were maintained in contact fungicides for each treatment whereas; five plates were maintained in systemic and combination fungicides for each treatment.. The control plates without fungicide were also inoculated and incubated. The plates were kept for incubation at $26 \pm 2{ }^{\circ} \mathrm{C}$ temperature. The observations on colony diameter were recorded after 10 days.

The antagonistic potential of Bioagents viz., Trichoderma asperellum, Trichoderma harzianum, Pseudomonas fluorescens, Pseudomonas putida, Bacillus subtilis and Bacillus vezelensis were tested by dual culture technique (Utkhede and Rahe, 1983). For this $20 \mathrm{ml}$ of sterilized, melted and cooled medium was poured in each petriplates and allowed to solidify and the plates were inoculated with $5 \mathrm{~mm}$ disc of 7 days old growth of fungal biocontrol agents with the help of sterilized cork borer and subsequently inoculated with $5 \mathrm{~mm}$ disc of 7 days old culture of Alternaria solani a opposite corner of the plates, keeping $15 \mathrm{~mm}$ distance from periphery. The bacterial antagonists were streaked with the help of sterilized inoculating loop at one end of the PDA petriplates. After $24 \mathrm{hrs}$ of incubation just opposite to the bacterial streak $5 \mathrm{~mm}$ disc of pathogen was 
placed with the help of sterilized cork borer. The inoculation of pathogen alone on the center in the plates serves as control. Three replication of each treatment including the control were maintained. These plates were incubated at $26 \pm 2{ }^{\circ} \mathrm{C}$ in BOD incubator.

The percent inhibition mycelial growth of fungus was calculated by using the formula given by Vincent (1947).

$$
I=\frac{C-T}{C} \times 100
$$

Where,

I- Percent inhibition of mycelial growth

C- Growth of mycelium in control

$\mathrm{T}$ - Growth of mycelium in treatment

\section{Results and Discussion}

In the absence of resistant cultivars, use of fungicides to manage the disease is the best alternative when the disease is epidemic. The fungicides has to be used judiciously according to need of the situation and pathogen. Availability of new group of chemicals necessitates evaluation under in vitro conditions to know their efficacy and initiate spray schedule in field conditions.

The result clearly indicates that there was significant difference among the contact fungicides in inhibiting the radial growth of the A. solani. Among the different contact fungicides evaluated against test fungi Mancozeb (78.61\%) was significantly superior over other two fungicides. Chlorothalonil has recorded $36.57 \%$ inhibition and the least inhibition was noticed in case of Mandipropamid which has recorded $18.80 \%$ inhibition. Among the different concentration of contact fungicides evaluated against $A$. solani, Mancozeb at $0.25 \%$ recorded maximum inhibition of $80.83 \%$ followed by Chlorothalonil $(40.56 \%)$ and least was recorded in Mandipropamid (26.39\%) (Fig. 1-5 and Table 1-3).

Table.1 In vitro evaluation of contact fungicides against Alternaria solani

\begin{tabular}{|c|c|c|c|c|}
\hline \multirow{2}{*}{ Fungicides } & \multicolumn{3}{|c|}{ Per cent inhibition of mycelial growth } & \multirow{2}{*}{ Mean } \\
\cline { 2 - 5 } & \multicolumn{3}{|c|}{ Concentration } \\
\cline { 2 - 5 } & $\mathbf{0 . 1 5} \%$ & $\mathbf{0 . 2 0 \%}$ & $\mathbf{0 . 2 5 \%}$ & \\
\hline \multirow{2}{*}{ Chlorothalonil 75\% WP } & 29.72 & 39.44 & 40.56 & 36.57 \\
\hline Mancozeb 75\% WP & $(32.94)$ & $(38.81)$ & $(39.56)$ & $(37.10)$ \\
\hline Mandipropamid 23.4\% SC & 75.28 & 79.72 & 80.83 & 78.61 \\
& $(60.40)$ & $(63.13)$ & $(64.04)$ & $(62.52)$ \\
\hline Mean & 9.44 & 20.56 & 26.39 & 18.80 \\
& $(17.77)$ & $(26.73)$ & $(30.90)$ & $(25.13)$ \\
\hline
\end{tabular}

\begin{tabular}{|c|c|c|c|}
\hline & Fungicides & Concentration & Fungicides x Concentration \\
\hline S Em \pm & 0.14 & 0.14 & 0.23 \\
\hline CD @ 1\% & 0.51 & 0.51 & 0.88 \\
\hline
\end{tabular}

* Figures in the parenthesis are angular transformed values 
Table.2 In vitro evaluation of systemic and combination fungicides against Alternaria solani at 10DAI

\begin{tabular}{|c|c|c|c|c|}
\hline \multirow{2}{*}{ Fungicides } & \multicolumn{3}{|c|}{ Per cent inhibition of mycelial growth at 10DAI } & \multirow{2}{*}{ Mean } \\
\cline { 2 - 5 } & \multicolumn{3}{|c|}{ Concentration \% } \\
\cline { 2 - 5 } Difenoconazole 25\%EC & 74.10 & 0.10 & 0.15 & 77.78 \\
& $(59.41)$ & 76.94 & $(61.88)$ & $(60.87)$ \\
\hline Hexaconazole 5\% EC & 86.11 & 86.22 & 86.22 & 86.15 \\
& $(68.12)$ & $(68.21)$ & $(68.21)$ & $(68.15)$ \\
\hline Pyraclostrobin 20\% WG & 53.99 & 58.33 & 58.89 & 57.07 \\
& $(47.29)$ & $(49.80)$ & $(50.12)$ & $(49.07)$ \\
\hline Tetraconazole 3.8\% EW & 77.66 & 80.83 & 82.78 & 80.42 \\
& $(61.81)$ & $(64.06)$ & $(65.50)$ & $(63.79)$ \\
\hline Thiafluzamide 24\%SC & 56.76 & 71.39 & 70.56 & 66.23 \\
& $(48.91)$ & $(57.67)$ & $(57.14)$ & $(54.57)$ \\
\hline Fluxapyraxad 250 + & 76.57 & 79.72 & 80.56 & 78.95 \\
Pyraclostrobin 250 SC & $(61.06)$ & $(63.24)$ & $(63.84)$ & $(62.72)$ \\
\hline Trifloxystrobin 25 + & 82.39 & 83.33 & 85.00 & 83.57 \\
Tebuconazole 50\% WG & $(65.21)$ & $(65.91)$ & $(67.23)$ & $(66.11)$ \\
\hline Mean & 72.53 & 76.67 & 77.38 & $(61.97)$ \\
\hline
\end{tabular}

* Figures in the parenthesis are angular transformed values

Table.3 In vitro evaluation of bio agents against Alternaria solani

\begin{tabular}{|l|c|c|}
\hline \multirow{2}{*}{ Fungicides } & \multicolumn{2}{|c|}{ Per cent inhibition of mycelial growth } \\
\cline { 2 - 3 } & 3 DAI & 5 DAI \\
\hline Bacillus subtilis & 29.74 & 42.49 \\
& $(33.02)$ & $(41.91)$ \\
\hline Bacillus vezelensis & 46.79 & 62.76 \\
& $(43.16)$ & $(55.36)$ \\
\hline Pseudomonas fluorescens & 21.00 & 42.19 \\
& $(27.22)$ & $(40.50)$ \\
\hline Pseudomonas putida & 38.46 & 43.13 \\
& $(38.30)$ & $(41.05)$ \\
\hline Trichoderma asperellum & 62.98 & 69.69 \\
& $(49.11)$ & $(56.65)$ \\
\hline Trichoderma harzianum & 63.91 & 67.51 \\
& $(53.30)$ & $(55.27)$ \\
\hline SEm \pm & 1.22 & 1.10 \\
\hline CD @ 1\% & 4.90 & 4.41 \\
\hline
\end{tabular}

* Figures in the parenthesis are angular transformed values 
Fig.1 In vitro evaluation of non systemic fungicides against Alternaria solani

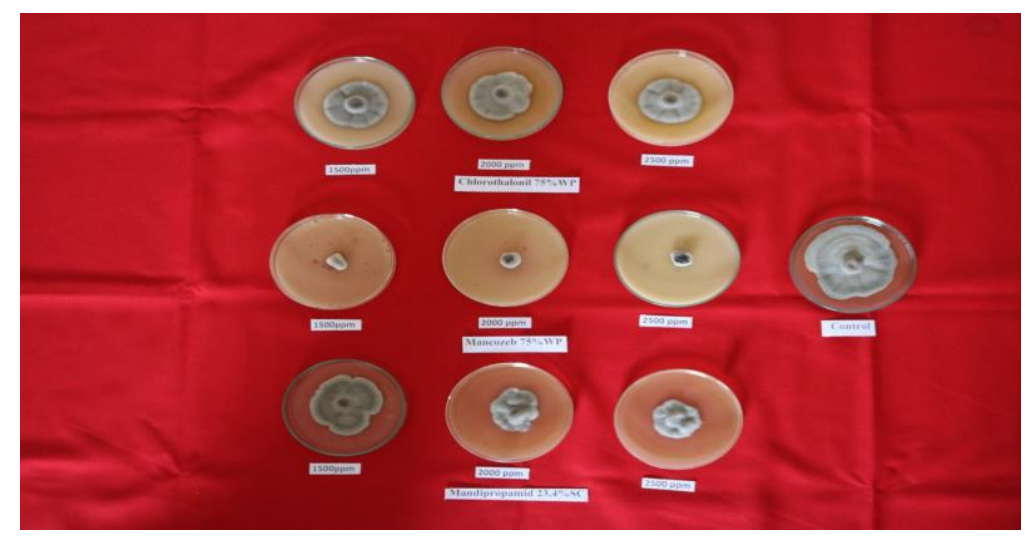

Fig.2 In vitro evaluation of systemic fungicides against Alternaria solani

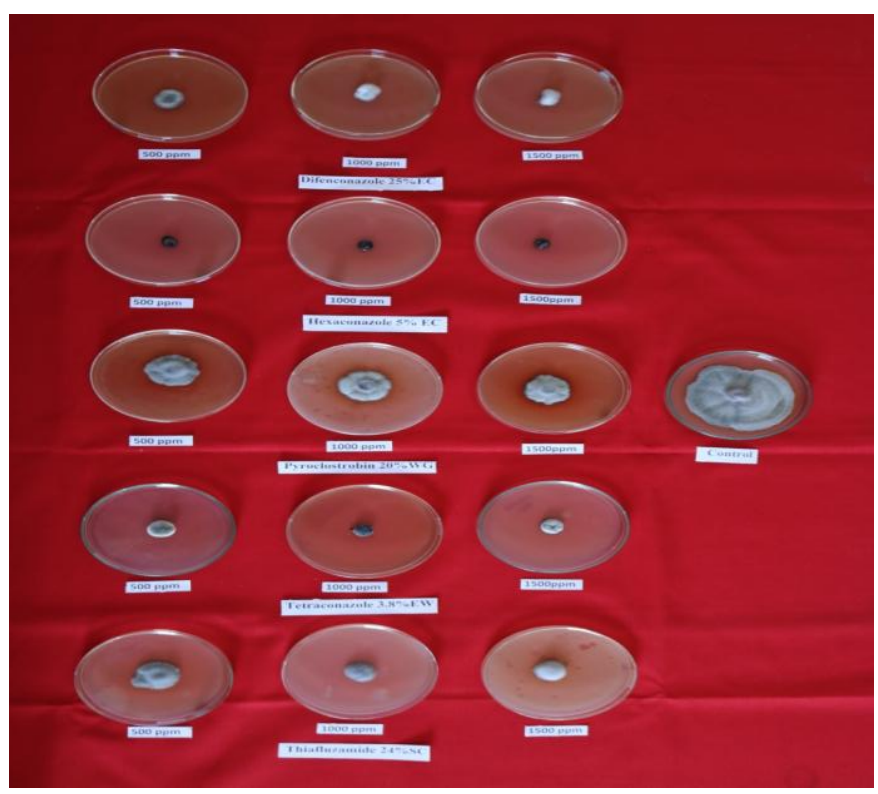

Fig.3 In vitro evaluation of combination fungicides against Alternaria

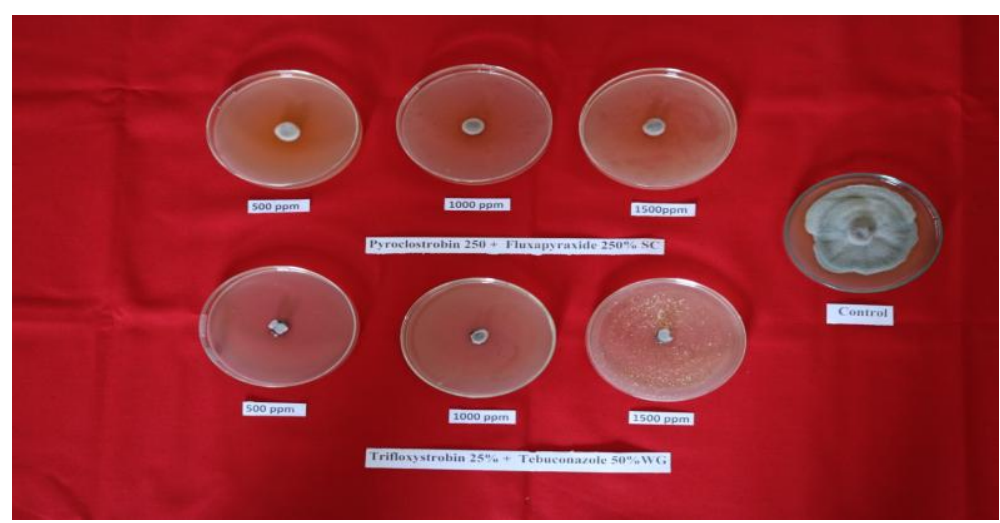


Fig.4 In vitro evaluation of fungal bio agents against Alternaria solani

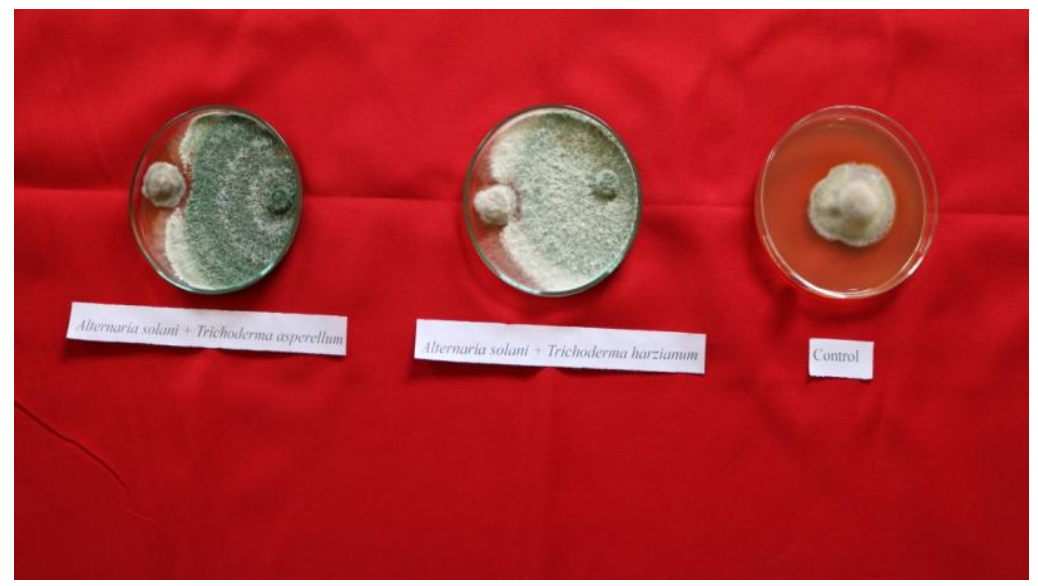

Fig.5 In vitro evaluation of bacterial bio agents against Alternaria solani

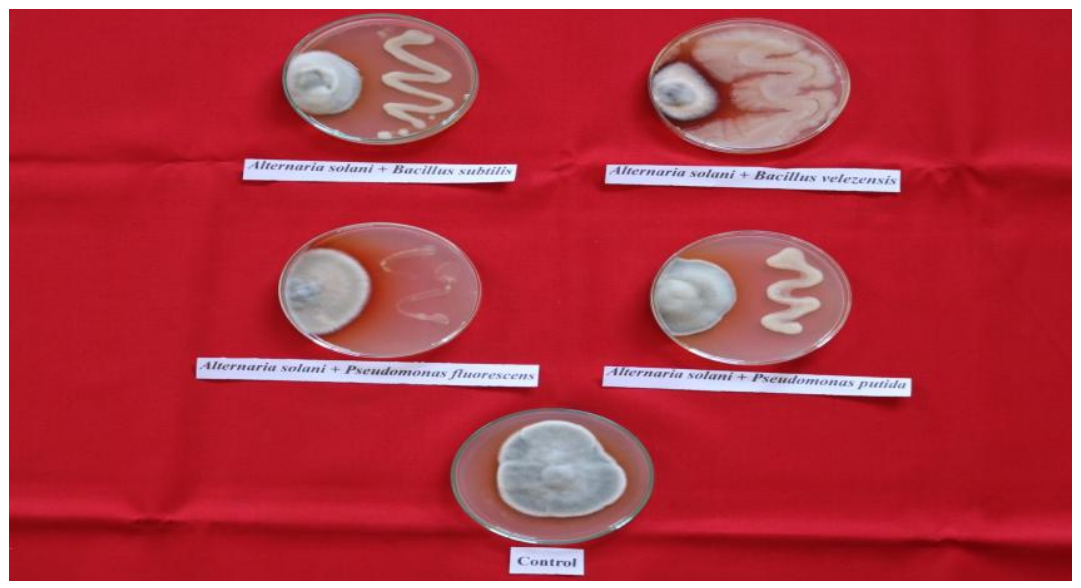

Among the five systemic and two combination fungicides evaluated against A.solani Hexaconazole @ $0.1 \%$ and $0.15 \%$ has recorded maximum inhibition of mycelial growth of test fungi $(86.22 \%)$ followed by $85.00 \%$ inhibition was recorded in Trifloxystrobin $25+$ Tebuconazole $50 \%$ WG @ $0.15 \%$. Among the other systemic and combination fungicides evaluated Tetraconazole 3.8\%EW @ 015\% recorded $82.78 \%$ and Fluxapyraxad $250+$ Pyraclostrobin 250 SC @ 0.15\% recorded $80.56 \%$ per cent inhibition. The least percent inhibition of $53.99 \%$ was recorded in Pyraclostrobin 20\%WG @ 0.05\%. In overall among the different systemic and combination fungicides maximum mean inhibition of mycelia of $A$. solani was recorded in Hexaconazole (86.15\%), followed by $83.57 \%$ in Trifloxystrobin $25+$ Tebuconazole 50\% WG and least of $57.07 \%$ was recorded in Pyraclostrobin20\%WG (Table. 2). The results also indicated that the inhibition percentage was increased by increasing the concentration fungicides tested. The results are in agreement with results of Roopa et al., 2014, Arun kumar 2006, reported the effectiveness of Mancozeb@0.2\% and Hexaconazole @0.1\% in inhibiting the mycelial growth of test fungi.

Six antagonistic agents evaluated against $A$. solani through dual culture technique as mentioned in material and methods. The results of the study were presented in Table 3 . 
Results clearly shows that among the different antagonistic organisms evaluated maximum inhibition of mycelial growth of $A$. solani was recorded in Trichoderma asperellum (69.69 $\%)$ followed by Trichoderma harzianum (67.51\%). Among the four bacterial bio agents evaluated against $A$. solani, Bacillus vezelensis has recorded $62.76 \%$ followed by Pseudomonas putida (43.13\%) and the least per cent inhibition of mycelial growth was noticed in Pseudomonas fluorescens (42.19\%) at 5 days after incubation. The effectiveness of Trichoderma harzianum, Trichoderma viride against $A$. solani was reported by Babu et al., 2000 and Yadhav et al., 2018.

\section{References}

Anonymous, 2018, Horticultural statistics at a glance 2018, Pub: Ministry of Agriculture and farmer welfare, GOI, 458.

Arunkumar, K.T., 2006, Studies on Alternaria solani (Ellis and Martin) Jones and Grout causing early blight of tomato, M.Sc. (Agri.) Thesis. Univ. Agril. Sci., (India).

Babu, S., Seetharaman, K., Nandakumar, R. and Johnson, I., 2000, Efficacy of fungal antagonists against leaf blight of tomato caused by Alternaria solani (Ell. and Mart.). Journal of Biological control. 14(2): 79-81.

Chandravanshi, S.S., Singh, B.P. and Thakur, M.P., 1994. Persistence of different fungicides used against Alternaria alternata in tomato. Indian Phytopathol. 47(3): 241-244.

Datar, V.V. and Mayee, C.D., 1981, Assessment of loss in tomato yield due to early blight. Indian Phytopathology.34: 191-195

Nene, V.I. and Thapliyal, P.N., 1979, Fungicides in plant disease control. Oxford and IBH publishing company. New Delhi 507p.

Roopa, R.S., Yadaalli, K.B. and Kavyashree, M.C., 2014, Evaluation of natural plant extracts, antagonists and fungicides against early blight caused by Alternaria solani in vitro. The Bioscan, 6 (3): 1309-1312.

Utkhede, R.S. and Rahe, J.E., 1983, Interactions of antagonist and pathogen I biological control of onion white rot. Phytopathology, 73(6): 890-893.

Vincent, J.M, 1947, Distortion of fungal hyphae in the presence of certain inhibitors. Nature. 159: 239-241.

Vloutoglou, I. and Kalogerakis, S.N., 2000, Effect of inoculum concentration, wetness duration and plant age on development of early blight (Alternaria solani) and on shedding of leaves in tomato plants. Plant Pathology. 49: 339-345.

Yadav, V.K., Kumar, V. and Mani.A., 2018, Evaluation of fungicides, biocontrol agents and plant extracts against early blight of potato caused by Alternaria solani. International journal of chemical studies. 6(1):1227-1230.

\section{How to cite this article:}

Sudarshan, G. K., M. S. Nagaraj, N. Thammaiah, S. B. Yogananada, A. P. Mallikarjuna Gowda and Prasanna Kumar, M. K. 2020. In vitro Efficacy of Fungicides and Bioagents against Early Blight of Tomato caused by Alternaria solani. Int.J.Curr.Microbiol.App.Sci. 9(09): 1490-1496. doi: https://doi.org/10.20546/ijcmas.2020.909.188 